\title{
Anionic Iron(III) Porphyrin Immobilized on/into Exfoliated Macroporous Layered Double Hydroxides as Catalyst for Oxidation Reactions
}

\author{
Shirley Nakagaki, ${ }^{*, a}$ Kelly A. D. F. Castro, ${ }^{a}$ Geani M. Ucoski, ${ }^{a}$ Matilte Halma, ${ }^{a, b}$ \\ Vanessa Prévot, ${ }^{a}$ Claude Forano ${ }^{b}$ and Fernando Wypych ${ }^{a}$ \\ ${ }^{a}$ Laboratório de Química Bioinorgânica e Catálise; Universidade Federal do Paraná(UFPR), \\ CP 19081, CEP 81531-990 Curitiba-PR, Brazil \\ ${ }^{b}$ Institut de Chimie de Clermont-Ferrand, Clermont Université, Université Blaise Pascal, BP 10448, \\ F-63000 Clermont-Ferrand, CNRS, UMR6296, ICCF, BP 80026, F-63171 Aubiere, France
}

\begin{abstract}
A oxidação de substratos orgânicos é uma importante classe de reações explorada visando a produção de insumos industriais tais como epóxidos, álcoois e cetonas. As metaloporfirinas são compostos com reconhecida atividade catalítica que mimetizam processos de oxidação que ocorrem em seres vivos. A sua imobilização em diferentes sólidos robustos e inertes permite a recuperação e reuso do catalisador em processos catalíticos heterogêneos. Hidróxidos duplos lamelares (LDHs) são materiais inorgânicos constituídos de hidróxidos de metais di e trivalentes, resultando em lamelas bidimensionais carregadas positivamente. Neste trabalho reportamos a preparação de catalisadores baseados na imobilização de ferroporfirina (FeP) em LDH macroporoso (LDHM) obtido pelo método de co-precipitação usando poliestireno como template, reconstrução de óxidos e esfoliação (LDHME). A imobilização da FeP no LDH intercalado com ânions nitrato obtido pelo método de co-precipitação também é reportada. Os sólidos obtidos foram caracterizados e investigados como catalisadores na oxidação do cicloocteno e cicloexano.
\end{abstract}

The oxidation of organic substrates via catalytic routes is an important class of reactions to produce industrial input materials such as epoxides, alcohols, and ketones. Metalloporphyrins display recognized catalytic activity that mimics oxidation processes in living organisms. Their immobilization in different inert supports allows their recovery and reuse in heterogeneous catalytic processes. Layered double hydroxides (LDHs) are inorganic materials consisting of di- and trivalent metal hydroxides that afford bidimensional positively charged layers. This work reports on the preparation of the solid based on macroporous LDHs (LDHMs) by the co-precipitation method, which involved the use of polystyrene as template, oxides reconstruction, and exfoliation, to furnish LDHME. We also describe the immobilization of an iron(III) porphyrin (FeP) in LDHME and in LDH intercalated with nitrate anions, obtained by the co-precipitation method. Application of the immobilized catalysts in $(Z)$-cyclooctene and cyclohexane oxidation will help to assess their catalytic activity.

Keywords: porphyrin, macroporous LDH, oxidation, biomimetic reaction, heterogeneous catalysis

\section{Introduction}

The family of enzymes collectively known as cytochrome $\mathrm{P} 450$ monooxygenases bear a heme prosthetic group and participate in different catalytic processes, mainly oxidative metabolism of endogenous/exogenous products in mammals. ${ }^{1-5}$

\footnotetext{
*e-mail: shirleyn@ufpr.br
}

Over the last years, researchers have made great efforts to develop routes that can generate robust synthetic metalloporphyrins (MPs), ${ }^{6-10}$ aiming to mimic biological enzymes such as cytochrome P450 (biomimetic approach). Indeed, MPs can efficiently and selectively catalyze hydrocarbon oxidation. ${ }^{11}$ Some of these MPs are based on the structure of meso-tetraphenylporphyrin $\left[\mathrm{H}_{2}(\mathrm{TPP})\right]$.

The high efficiency and selectivity of MPs have motivated the proposition of technological catalytic systems based on this versatile family of oxidation catalysts. 
Guo et al. developed and patented a process based on MP and atmospheric dioxygen to oxidize cyclohexane under mild conditions, ${ }^{12}$ as cited by Guan Huang et al..${ }^{13}$ Although information about this process is scarce in the literature, its successful implementation in the industry took place in $2003 .{ }^{13}$

The first MP-based catalytic system relied on the Fe(III) complex $[\mathrm{Fe}(\mathrm{TPP}) \mathrm{Cl}]$ as catalyst and iodosylbenzene $(\mathrm{PhIO})$ as oxidant $;{ }^{14}$ it mimicked cytochrome $\mathrm{P} 450$ in many reactions. Since then, the use of MPs, specially FePs and MnPs, in oxidative systems $s^{6-11,14-21}$ has attracted considerable attention, because these complexes can effectively and selectively catalyze a series of oxidation reactions in homogeneous medium, among which epoxidation and hydroxylation stand out. ${ }^{15-21}$

Despite their efficiency in homogeneous systems, the use of this family of complexes in solution has raised concerns. In homogeneous media, secondary reactions (e.g., destructive oxidation of the complex and MP dimerization, among others) can deactivate the catalytic species. ${ }^{10}$ Another difficulty posed by homogeneous catalysts is their recovery, reuse, and recycling, which could prevent the design of a technological process. ${ }^{8,15,18}$ To minimize such problems, researchers have turned to the synthesis of new robust and resistant porphyrin structures ${ }^{10,22}$ as well as to immobilization of these catalysts in different inorganic supports. ${ }^{22-33}$

Catalyst immobilization can facilitate catalyst recovery from the reaction medium, to enable their reuse and recycling. ${ }^{17,33-39}$ This is particularly attractive from an economical and environmental viewpoint. In this context, layered double hydroxides (LDHs) have emerged as interesting supports to immobilize a variety of MPs. . $^{18,23,40-44}$

LDHs are synthetic layered compounds that contain divalent and trivalent metal cations [M(II) and $\mathrm{M}(\mathrm{III})]$ in a structure derived from the mineral brucite. In LDHs, M(III) metal ions replace part of the M(II) metals in the brucitelike structure, to give excess positive charge in the layers, counterbalanced by intercalating hydrated anions..$^{24,40,44-49}$ Some hydrogen-bonded water molecules may occupy the free space that remains in the interlayer region, which stabilizes the structure.

Chemical modification of the support or the MP with suitable organic groups can confer enhanced stability to the catalyst-support assembly. Some kind of interaction involving the modifier on the support and/or on the MP might occur, which shall not only increase the rate of MP immobilization, ${ }^{40}$ but also provide a new solid catalyst with unprecedented efficiency and selectivity. $8,18,50$

There has been a recent surge in scientist's interest in nanostructured LDHs. This type of solid can be achieved by controlling the textural properties of the material in terms of morphology, particle size, specific area, and porosity. A colloidal crystal template method has produced tridimensional ordered macroporous MgAl-LDHs. ${ }^{41,51-53}$ Our group has already intercalated different anionic FePs in macroporous LDHs, to obtain more efficient and selective catalysts for heterogeneous hydroxylation and epoxidation reactions than their homogeneous counterparts. ${ }^{18} \mathrm{Co}$ precipitation using a template like polystyrene spheres furnishes an LDH structure bearing macropores, which is suitable for immobilization of countless FePs. ${ }^{41}$

In this work, we have prepared two solids by immobilizing the [Fe(TDCSPP)Cl] (Figure 1) - FeP - in different LDH supports, namely LDH containing intercalated nitrate anions $\left(\mathrm{LDH}-\mathrm{NO}_{3}\right)$ and exfoliated macroporous $\mathrm{LDH}$ (LDHME) (the iron porphyrin [Fe(TDCSPP)Cl] will be abbreviated as FeP by simplification; in this representation charges and counter ion $\mathrm{Cl}^{1-}$ are omitted). Because these solids have the same composition, but different structures, we investigated their catalytic activity in the oxidation of two model substrates, (Z)-cyclooctene and cyclohexane, by $\mathrm{PhIO}$.

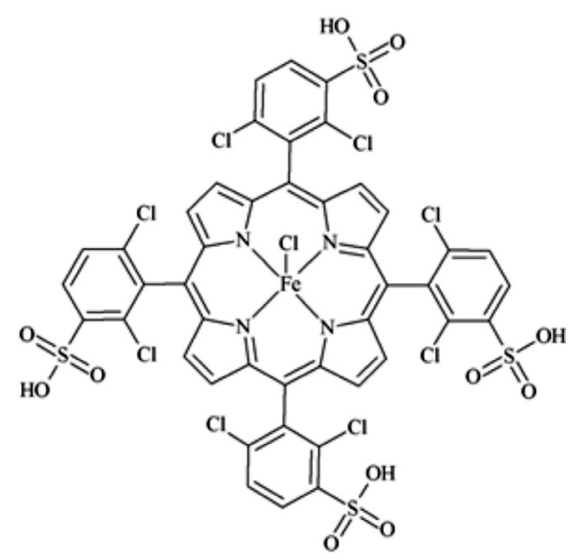

Figure 1. Schematic representation of the molecular structure of $\mathrm{FeP}$ ([Fe $\left.\mathrm{FII}^{\mathrm{III}}(\mathrm{TDCSPP}) \mathrm{Cl}\right]$ employed in this work, where $($ TDCSPP $)=5,10,15,20$-tetrakis(2,6-dichloro-3-sulfonate phenyl) porphyrin. The sulfonate groups are deprotonated in solution.

\section{Experimental}

\section{Materials}

All the chemicals used in this study were purchased from Aldrich, Sigma or Merck and were of analytical grade. Iodosylbenzene (PhIO) was synthesized by hydrolysis of iodosylbenzene diacetate, ${ }^{54}$ and the obtained solid was carefully dried under reduced pressure and kept at $5{ }^{\circ} \mathrm{C}$. LDH- $\mathrm{NO}_{3}$ and the macroporous LDH (LDHM) were synthesized as described previously by our research group. ${ }^{40-42}$ 
The free-base porphyrin [5,10,15,20-tetrakis(2,6dichloro-3-sulfonate phenyl)porphyrin], or [ $\mathrm{H}_{2}$ (TDCSPP)], was synthesized, purified, and characterized as previously described. ${ }^{55,56}$ The corresponding FeP, [ $\mathrm{Fe}^{\mathrm{III}}$ (TDCSPP)Cl], was obtained by inserting iron ion from ferrous chloride tetrahydrate into the free-base porphyrin ligand in dimethylformamide (DMF), as described by Adler, Longo, and Kobayashi. ${ }^{57,58}$ It is expected that the Fe ${ }^{\text {II }} \mathrm{P}$ complex is

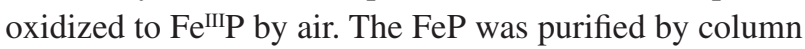
chromatography on Sephadex; deionized water was used as eluent. The metalloporphyrin was characterized by UV-Vis and electron paramagnetic resonance (EPR) spectroscopies. UV-Vis: [Fe(TDCSPP)Cl] (deionized water) $390 \mathrm{~nm}$ $\left(\varepsilon=6.4 \times 10^{4} \mathrm{~L} \mathrm{~mol}^{-1} \mathrm{~cm}^{-1}\right)$.

\section{Preparation of the solid LDHME and intercalation of the FeP}

To obtain LDHME, the previously synthesized LDHM $^{40,41}$ was subjected to exfoliation. ${ }^{23,40}$ Shortly, $10 \mathrm{~mL}$ of formamide and $25 \mathrm{mg}$ of solid LDHM were mixed in an Erlenmeyer flask, and the mixture was stirred in an ultrasound bath for $2 \mathrm{~h}$. An almost translucent milky suspension emerged, which suggested the formation of macroporous LDH by exfoliation (solid LDHME). The solid anionic FeP $\left(3.8 \times 10^{-6} \mathrm{~mol}\right)$ was added to the suspension, and the mixture was kept under magnetic stirring for $24 \mathrm{~h}$. A reddish brown solid (FeP-LDHME) arose. This solid was separated from the solution by centrifugation and extensively washed with water, until a colorless washing solution was achieved. The supernatants resulting from the washing process were collected and quantitatively analyzed by UV-Vis spectroscopy, to determine the FeP loading in the support.

Immobilization of $\mathrm{FeP}$ in $\mathrm{LDH}-\mathrm{NO}_{3}$

LDH- $\mathrm{NO}_{3}(\mathrm{Mg} / \mathrm{Al}$ at a 3:1 molar ratio) was prepared according to a methodology previously described by our group. ${ }^{40} \mathrm{FeP}$ immobilization was conducted by dispersing LDH- $\mathrm{NO}_{3}{ }^{40}$ (about $30 \mathrm{mg}$ ) in water $(10 \mathrm{~mL}$ ), which was followed by addition of the FeP (about $3.9 \times 10^{-6} \mathrm{~mol}$ ). The suspension was refluxed and stirred for $2 \mathrm{~h}$. After that, the resulting solid was filtered and washed with water. The supernatant was analyzed by UV-Vis spectroscopy, to quantify the FeP that could have been removed from the matrix by leaching. The bright brown solid labeled as $\mathrm{FeP}-\mathrm{LDH}-\mathrm{NO}_{3}$ was dried at $60{ }^{\circ} \mathrm{C}$ for $48 \mathrm{~h}$.

\section{Catalytic oxidation reactions}

Catalytic oxidation reactions were carried out in a $2 \mathrm{~mL}$ thermostatic glass reactor equipped with a magnetic stirrer, placed inside a dark chamber. The oxidation of (Z)-cyclooctene (previously purified on alumina column) and cyclohexane by $\mathrm{PhIO}$ was accomplished in the presence of the catalyst FeP-LDH-NO $\mathrm{N}_{3}$ or FeP-LDHME. In a standard experiment, the solid catalyst (FeP-LDH- $\mathrm{NO}_{3}$ or FeP-LDHME) and the oxidant (FeP/PhIO molar ratio 1:50) were suspended in $400 \mu \mathrm{L}$ of solvent (dichloromethane/ acetonitrile 1:1 mixture, v/v) and degassed with argon for $15 \mathrm{~min}$, inside a $2 \mathrm{~mL}$ vial. The reaction started after addition of the substrate (FeP/substrate molar ratio 1:5000); the oxidation reaction was performed under magnetic stirring for $1 \mathrm{~h}$. At the end of the reaction, sodium sulfite acetonitrile saturated solution $(50 \mu \mathrm{L})$ was added to the reaction mixture, to eliminate excess $\mathrm{PhIO}$. The supernatant containing the reaction products was separated from the solid catalyst by centrifugation and transferred to a volumetric flask. The solid catalyst was washed several times with dichloromethane and acetonitrile, to extract any substrate and reaction products that might have remained adsorbed onto the solid catalyst. The washing solutions were added to the previously separated reaction supernatant, and the products and reagents content in these combined solutions was analyzed by gas chromatography, using $n$-octanol (acetonitrile solution, $1.0 \times 10^{-2} \mathrm{~mol} \mathrm{~L}^{-1}$ ) of high purity degree (99.9\%) as internal standard. Product yields were based on the mass of PhIO added to each reaction. Control reactions were carried out using this same procedure, as follows: (a) substrate only, (b) substrate + $\mathrm{PhIO}$, and (c) substrate + $\mathrm{PhIO}+\mathrm{LDH}-\mathrm{NO}_{3}$ or LDHME (supports without FeP). A similar procedure was adopted to test the $\mathrm{FeP}$ as homogeneous catalyst.

All the heterogeneous catalysts were exhaustively washed and dried for reuse in further reactions using the same procedure described above.

\section{Characterization techniques}

Scanning electron microscopy (SEM) characteristics of the samples were imaged on either a JEOL 5190 microscope operated at $15 \mathrm{keV}$ or a JEOL JSM-6360LV operating $15 \mathrm{keV}$.

X-ray powder diffraction patterns (XRPD) were recorded in the reflection mode on a Shimadzu XRD-6000 diffractometer operating at $40 \mathrm{kV}$ and $40 \mathrm{~mA}$; $\mathrm{CuK} \alpha$ radiation $(\lambda=1.5418 \AA)$ and a dwell time of $1^{\circ} \mathrm{min}^{-1}$ were employed.

Electronic spectra (UV-Vis) were obtained on a Cary-Varian 100 Bio and Shimadzu UV-2501PC spectrophotometer, in the $200-800 \mathrm{~nm}$ range.

EPR measurements of the powder materials were accomplished on an EMX microX spectrometer (standard 
concavity: 4102-SP and $9.5 \mathrm{GHz} \mathrm{X}$ band frequency), at room temperature or at $77 \mathrm{~K}$ (in liquid $\mathrm{N}_{2}$ ).

Products from the catalytic oxidation reactions were quantified on a gas chromatograph Agilent 6850 (FID detector) equipped with a capillary column DB-WAX (J\&W Scientific). Quantitative analyses were based on internal standards.

\section{Results and Discussion}

Preparation of $\mathrm{LDH}-\mathrm{NO}_{3}$ and LDHM relied on the co-precipitation methodology without previous intercalation/functionalization of the inorganic matrix with organic molecules, as detailed by our group in recent publications. ${ }^{40,41}$ In particular, the synthesis of LDHM involved co-precipitation of divalent $\left(\mathrm{Mg}^{2+}\right)$ and trivalent $\left(\mathrm{Al}^{3+}\right)$ metal ions during the synthesis of $\mathrm{LDH}$; polystyrene beads (PS) served as template. ${ }^{41}$ After synthesis of the $\mathrm{LDH}-\mathrm{NO}_{3}$ solid, its calcination removed the polystyrene template that remained in the double oxides resulting from the calcined LDH. In the presence of dodecyl sulfate (DDS) solution, the lamellar structure of $\mathrm{LDH}-\mathrm{NO}_{3}$ re-emerged, whilst DDS intercalated within the macropores.

Immobilization of the $\mathrm{FeP}$ in $\mathrm{LDH}-\mathrm{NO}_{3}\left(\mathrm{FeP}-\mathrm{LDH}-\mathrm{NO}_{3}\right)$ or exfoliated macroporous LDH (FeP-LDHME)

$\mathrm{FeP}$ immobilization in $\mathrm{LDH}-\mathrm{NO}_{3}$ resulted in a brown solid with spectroscopic properties similar to those previously reported by us. ${ }^{40,46}$

Exfoliation of LDHM in the presence of formamide afforded a white colloidal (milky) suspension, designated LDHME. After an ion exchange reaction between this suspension and the anionic FeP, a reddish brown solid arose (FeP-LDHME). This solid was further characterized by X-ray diffraction (XRD), Fourier transform infrared (FTIR), UV-Vis, and SEM. The exfoliation process generated individual lamella (or monolamella), which could facilitate chemical modification or exchange of the anion present in the lamellar space. ${ }^{40,59}$ The formamide employed during the exfoliation process solvated the anions and intercalated between the lamella, which caused a rupture in the lamellar structure and consequently exfoliated the compound in the form of individual lamella. Indeed, Hibino ${ }^{59}$ described that formamide constitutes a good solvent for this purpose and dismisses the need for heating or reflux.

As expected, the anionic FeP successfully anchored in both $\mathrm{LDHME}$ and $\mathrm{LDH}-\mathrm{NO}_{3}$ : the negative charges in the structure of this FeP (Figure 1) effectively interacted with the positively charged layers of the solids. Obviously, this process did not exhaust the anionic exchange capacity of the solid matrixes, so part of the original anions still existed in the material.

To quantify the FeP loading in $\mathrm{LDH}-\mathrm{NO}_{3}$ and LDHME, we measured the amount of non-immobilized FeP in the combined solutions from the washings of the solids FeP-LDH-NO ${ }_{3}$ and FeP-LDHME by UV-Vis spectroscopy. The FeP loadings on LDH and LDHME were $1.53 \times 10^{-4}$ and $9.23 \times 10^{-5} \mathrm{~mol} \mathrm{FeP} \mathrm{g}^{-1}$ of matrix, respectively.

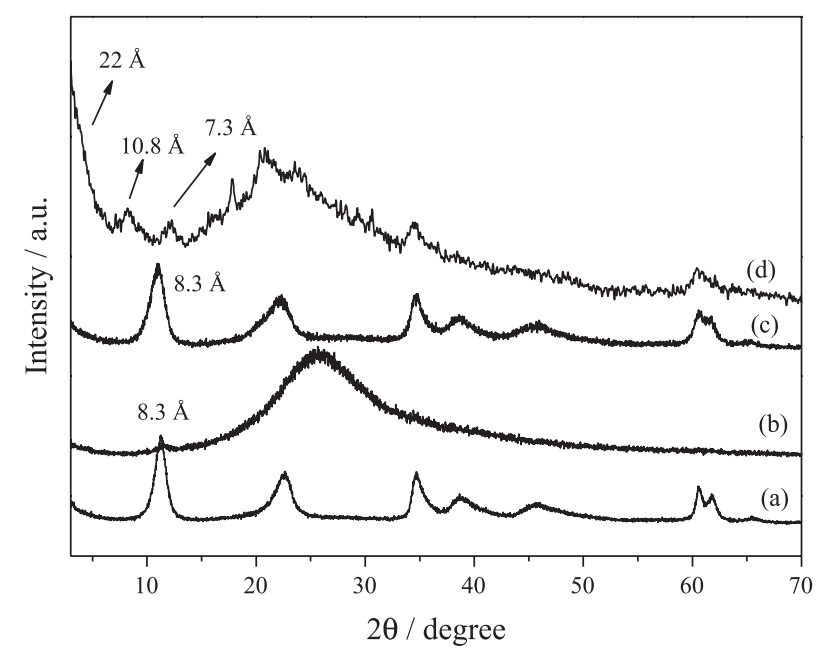

Figure 2. XRD of the solids (a) $\mathrm{LDH}-\mathrm{NO}_{3}$; (b) LDHME suspension; (c) FeP-LDH-NO $\mathrm{N}_{3}$; and (d) FeP-LDHME. The arrow indicates the peak region at $2 \theta$ values.

Figure 2 shows the XRD patterns of the solids before and after FeP immobilization. The solid resulting from FeP immobilization in $\mathrm{LDH}_{-} \mathrm{NO}_{3}$ (Figure 2c) exhibited an X-ray diffraction pattern similar to that obtained for $\mathrm{LDH}-\mathrm{NO}_{3}$ alone (Figure 2a), with a basal distance of approximately $8.3 \AA$. This distance corresponded to the presence of intercalated nitrate anions, indicating that the immobilized FeP did not replace these ions and probably localized on the surface of the layered crystals. ${ }^{10}$

LDHM (figure not shown) displayed reflections (001 and hkl) characteristic of hydrotalcite-like compounds, with a basal distance of $25.5 \AA$. These data agreed with literature values for DDS intercalated into LDHs. The XRD analysis of LDHME as a slurry revealed a halo in the $2 \theta$ region of 18 to $40^{\circ}$ after exfoliation, typical of amorphous compound in colloidal suspension. ${ }^{41}$ The phase obtained after ion exchange with the anionic FeP had basal spacing of approximately $22 \AA$, calculated from the higher order diffraction peak at $2 \theta$ values of $12.15^{\circ}$ $(7.28 \AA \times 3=21.85 \AA$ ca. $22 \AA$ ) (Figure 2d). Although not evident as indicated by an arrow in Figure 2, other two harmonic peaks related with the same basal distance $\left(8.22^{\circ}=10.76 \AA(10.76 \times 2=21.5 \AA) ; 12.15^{\circ}=7.28 \AA\right.$ 
$(7.28 \times 3=21.85 \AA))$ are a clear evidence that another peak occurs at $4.04^{\circ}(2 \theta)(21.87 \AA)$. This basal distance is close to the value reported in the literature when porphyrins are intercalated into $\mathrm{LDH}_{-} \mathrm{NO}_{3}$ (Figure 2c). Therefore, we cannot exclude FeP intercalation in the interlayer space of LDHME, but asserting that intercalation indeed took place in this case is difficult because intercalated DDS anions also exist in the matrix and produce similar basal spacing. Interestingly, DDS bilayers and FeP species exhibit high chemical and structural compatibility, so co-immobilization of this species could also occur, as recently described for the immobilization of this same FeP in LDHM. ${ }^{41}$ Besides this diffraction peak, the characteristic peak of $\mathrm{LDH}-\mathrm{NO}_{3}$ in the region of $60^{\circ}(2 \theta)$ appeared, indicating that exfoliated layers restacked (Figure $2 \mathrm{~d}$ ).

In general, the SEM images of LDHs predominantly intercalated with inorganic ions show particles agglomerated in the hexagonal form, known as "pink sand". However, if the LDH contains intercalated organic anions, the SEM images reveal layered crystals with round corners, ${ }^{40,60}$ which was the case with $\mathrm{LDH}-\mathrm{NO}_{3}$ (Figure 3a), a solid that contained submicrometric layered crystals.

Because FeP immobilization in both $\mathrm{LDH}-\mathrm{NO}_{3}$ and LDHME happened under rash conditions, the crystals should lose their original morphology and form agglomerates without any apparent order (Figure $3 \mathrm{~b}$ and $3 \mathrm{~d}$ ). In the case of LDHM (Figure 3c), part of the image showed the macroporous structure that resulted from removal of the polystyrene sphere, evidencing a honeycomb-like morphology. After exfoliation and restacking, even these structures disappeared, to reveal particles arranged in the form of a "house of cards", typical of exfoliated and restacked LDHs. ${ }^{61}$ Obviously, some of the layers remained stacked, to give the original crystals, as attested by XRD (Figure 2d).

The FTIR technique was inconclusive to ascertain the presence of the FeP on the surface or intercalated in the supports. Indeed, FeP-LDH-NO $\mathrm{N}_{3}$ and FeP-LDHME (in the Supplementary Information (SI) section) display the typical bands of FePs (region between 1200 and $1020 \mathrm{~cm}^{-1}$, typical of the $v_{\text {sym. }} \mathrm{S}-\phi$ and $v_{\text {asym. }} \mathrm{S}-\phi$ symmetric and asymmetric vibrations of the $\phi-\mathrm{SO}_{3}$ groups. ${ }^{62,63}$ The large intensity of the bands of the support in the region of $3000 \mathrm{~cm}^{-1}$ (surface hydroxyl groups and also water molecules in the interlamellar space), $1628 \mathrm{~cm}^{-1}$ (water molecules present in the interlayer space), and 1385 and $843 \mathrm{~cm}^{-1}$ (symmetric and asymmetric vibrations of intercalated nitrate, respectively) allied with the low FeP concentration in the support probably made difficult to observe the FeP bands. These bands occur between $1600-1370 \mathrm{~cm}^{-1}$, due to $\mathrm{vC}=\mathrm{C}$ phenyl and around $640 \mathrm{~cm}^{-1}$, attributed to out-of-the-plane C-H vibrations. ${ }^{40,63}$ For the solid FeP-LDHME, other bands were observed in the region of $2960-2840 \mathrm{~cm}^{-1}(\mathrm{vC}-\mathrm{H})$; around $1700 \mathrm{~cm}^{-1}(\mathrm{vC}=\mathrm{O})$ and $1600 \mathrm{~cm}^{-1}$ symmetric

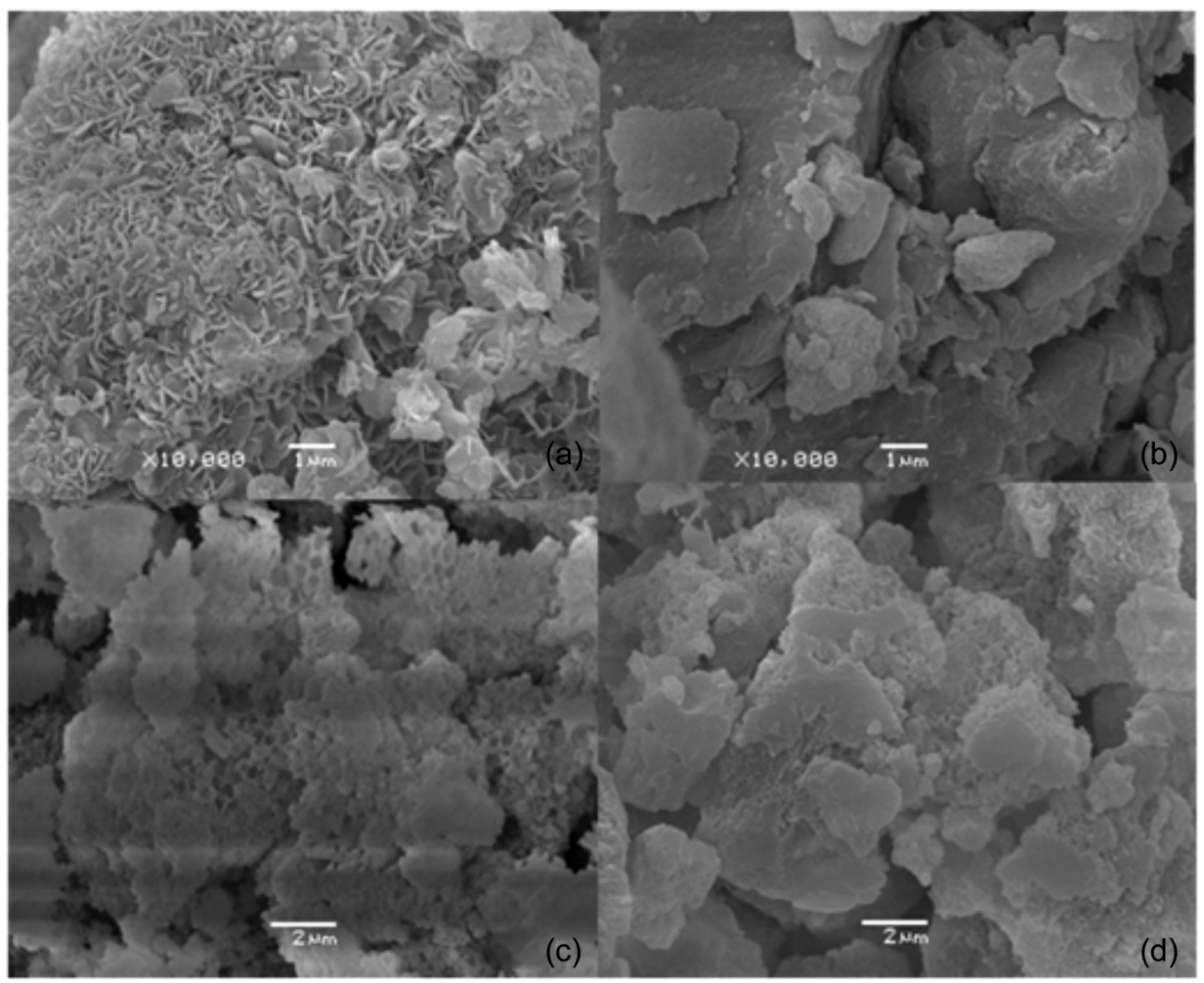

Figure 3. SEM micrographs of the solids (a) $\mathrm{LDH}-\mathrm{NO}_{3}$; (b) FeP-LDH-NO ; (c) LDHM, and (d) FeP-LDHME. 
angular deformation in the plane $\left(\mathrm{NH}_{2}\right)$ attributed the presence of formamide used in the exfoliation process.

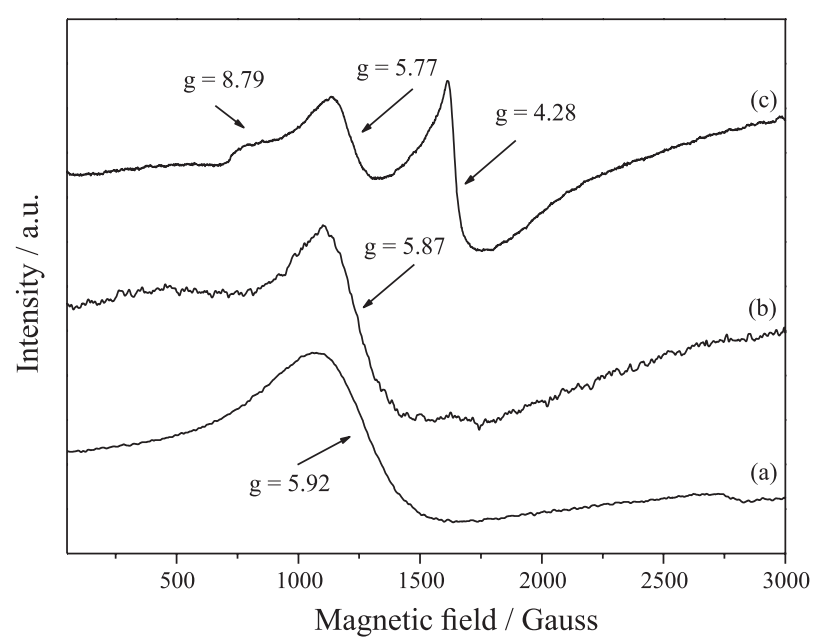

Figure 4. EPR spectrum of [Fe(TDCSPP)Cl] before and after $\mathrm{FeP}$ immobilization on LDHs: (a) [Fe(TDCSPP)Cl]; (b) FeP-LDH-NO ; and (c) FeP-LDHME.

For a system containing high-spin Fe(III), the combination of five unpaired electrons results in three Kramer doublets: $\pm 1 / 2, \pm 3 / 2$, and $\pm 5 / 2$. The extent to which these energy levels are occupied depends on the separating field and temperature. In a strong crystal field of tetragonal symmetry, the deployment parameter of the field is large, and only the transitions $\pm 1 / 2$ are viewable $\left(\mathrm{g}_{\perp}\right.$ and $\mathrm{g}_{/ /}=6.0$ and 2.0, respectively). ${ }^{64-66}$ However, if the local symmetry reduces from tetragonal to orthorhombic, for example, which distorts the porphyrin plane, other signs arise. Systems with maximum distortion display only one signal at $g=4.3$. The field separation can be described in terms of two parameters: D (axial separation) and $\mathrm{E}$ (rhombic splitting). The ratio between $\mathrm{D}$ and $\mathrm{E}$ may have values between 0 (axial symmetry) and 0.33 (rhombicity maximum) with different values of factor g. ${ }^{64-66}$

Figure 4 illustrates the EPR spectra of the solids obtained after FeP immobilization. The free FeP (Figure 4a) presented a signal in g ca. 6.0 (axial symmetry), typical of a high-spin 5/2 FeP complex. FeP immobilization in LDH and LDHME (Figures $4 \mathrm{~b}$ and $4 \mathrm{c}$ ) gave the characteristic signal of high-spin $\mathrm{Fe}(\mathrm{III})(\mathrm{S}=5 / 2)$, typical of axially symmetric FePs. ${ }^{17,52,67}$ A typical signal of $\mathrm{Fe}(\mathrm{III})$ with rhombic distortion $(\mathrm{g}=4.3)$ arose, which is usual in immobilized FeP systems. ${ }^{10,68}$ The estimated D/E ratio was 0.20 , which enabled assignment of the observed signals to transitions of the states $+-1 / 2+$ and $-3 / 2$, with $g$ values of $8.79,5.77$, and 4.28 .

The intense signal at $\mathrm{g}=4.28$ detected for solid FePLDHME originated from the greater distortion undergone by the FeP during the immobilization process. Such distortion may be associated with the necessity of the $\mathrm{FeP}$ structure to settle as close as possible to the matrix, to maximize its interactions with the positively charged layers of the support. ${ }^{17}$ Hence, EPR analysis confirmed the presence of $\mathrm{FeP}$ in the matrixes (Figures $4 \mathrm{~b}$ and $4 \mathrm{c}$ ) after the immobilization process and evidenced FeP distortions (Figure 4c).

UV-Vis analysis of the solid samples also attested that FeP existed in the support (Figure 5).

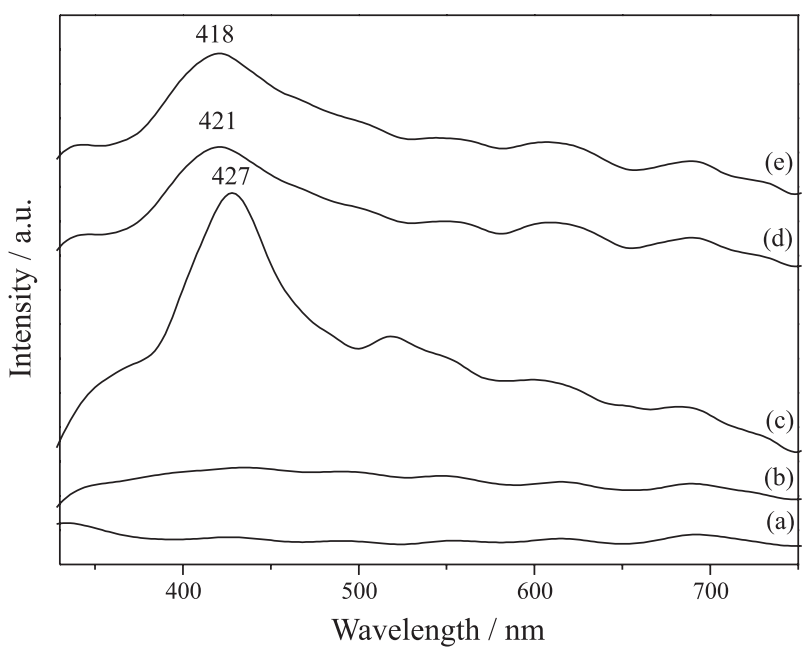

Figure 5. UV-Vis spectra of (a) LDH-NO (d) FeP-LDH-NO ${ }_{3}$; and (e) FeP-LDHME.

The spectra of the solids FeP-LDH-NO $\mathrm{N}_{3}$ and FePLDHME contained the Soret band characteristic of Fe(III) Ps in the region of $400 \mathrm{~nm}$. Other three bands appeared between 500 and $700 \mathrm{~nm}$ (Q bands).

Comparison of the spectra of the immobilized $\mathrm{FeP}$ with that of the free $\mathrm{FeP}$ revealed that immobilization promoted a blue shift of the Soret band. ${ }^{9,18,69}$ Such shifts may result from (i) FeP intercalation into the support, which may distort the structure of the complex, or (ii) interactions between the support surface and the FeP, which can cause steric constraints. Regardless of the immobilization mode, in both cases (FeP-LDH-NO ${ }_{3}$ and FeP-LDHME), the blue shift may have stemmed from interactions between the FeP plane and the support in an attempt of the complex to acquire a more planar conformation and maximize the electrostatic interaction. ${ }^{29}$ The Soret band of FeP-LDH- $-\mathrm{NO}_{3}$ shifted less markedly, leading to the conclusion that the FeP was less constrained in this support (Figure 5d).

Because we immobilized the FeP in previously prepared $\mathrm{LDH}-\mathrm{NO}_{3}$, and on the basis of XRD analysis, we inferred that the FeP bound at the surface of the layered crystals. In the case of LDHME, the FeP was added to a suspension of exfoliated macroporous LDH, so many individual layers were available to interact with the anionic FeP, which localized 
closer to the positive charges on the matrix (Figure 6). These results were in line with the EPR data, which had suggested that FeP-LDH-NO $\mathrm{N}_{3}$ displayed less rhombic distortion than FeP-LDHME (Figures $4 \mathrm{~b}$ and $4 \mathrm{c}$, respectively).

\section{Catalytic oxidation reactions}

The use of FePs as catalysts promotes $\mathrm{C}-\mathrm{H}$ bond activation by oxidation under biomimetic mild conditions and in the presence of a number of oxygen atom donors such as iodosylbenzene, ${ }^{8,11,14,16,28,70}$ hydrogen peroxide, ${ }^{71}$ and dioxygen, ${ }^{72,73}$ among others. Here, we decided to employ $\mathrm{PhIO}$ as oxygen donor because MP/PhIO is a classical biomimetic system that can produce the same intermediate catalytic species regardless of the FeP. ${ }^{6,11}$

The oxidation of (Z)-cyclooctene by MP/PhIO systems produces epoxide as the sole oxidation product, with no traces of allylic alcohol or ketone. ${ }^{74}$ For this reason, $(Z)$-cyclooctene is the substrate of choice when testing the activity of biomimetic catalytic systems involving MPs, and we also selected it to assay the efficiency and stability of the anionic FeP immobilized in both of the investigated supports. By employing this substrate, we also obtained initial information about accessibility to the activated iron site.

The activation of the highly inert $\mathrm{C}-\mathrm{H}$ bonds of cyclic alkanes, to obtain hydroxylated products, is one of the most remarkable reactions that natural and synthetic systems can accomplish. ${ }^{75}$ Indeed, C-H bond activation in alkanes calls for more drastic conditions than those necessary for alkene functionalization, which in turn allows one to differentiate between the performances of an MP catalyst in solution and the same MP catalyst immobilized in a solid support. Cyclohexane is also a very useful substrate to test the activity of $\mathrm{FeP} / \mathrm{PhIO}$ systems as its major oxidation products, cyclohexanol and cyclohexanone provides information about catalyst selectivity.
Table 1 presents the results from the oxidation of (Z)-cyclooctene and cyclohexane by $\mathrm{PhIO}$ catalyzed by FeP-LDH-NO ${ }_{3}$ and FeP-LDHME. We also evaluated the free $\mathrm{FeP}$ for comparison.

The immobilized FeP afforded excellent product yields for both $(Z)$-cyclooctene oxidation and cyclohexane hydroxylation, which were even better than the yields obtained with the free $\mathrm{FeP}$ in homogeneous solution (Table 1 runs 1, 2, and 4). All the reactions that involved FeP-based catalysts (runs 1 to 4 ) furnished considerably higher product percentages than the control reactions (runs 5 to 7), which confirmed that the catalytic activity of the studied catalysts was really due to the FeP.

The low solubility of anionic porphyrins like [Fe(TDCSPP)] in a $\mathrm{CH}_{2} \mathrm{Cl}_{2} / \mathrm{CH}_{3} \mathrm{CN}$ 1:1 solvent mixture certainly underlay the lower yields obtained with the free $\mathrm{FeP}$ in homogeneous medium (run 1) as compared with the immobilized FeP (runs 2 and 4). Another explanation for the difference between the catalytic performances of the $\mathrm{FeP}$ in homogeneous and heterogeneous media might be that the charged catalyst hinders the approach of the apolar substrates to the active metal center. Indeed, immobilization of the anionic $\mathrm{FeP}$ in the $\mathrm{LDH}-\mathrm{NO}_{3}$ and LDHME supports by electrostatic interaction may have minimized this effect in the case of the heterogeneous process, to improve the catalytic activity of the FeP. ${ }^{40,41}$

Interestingly, FeP-LDHME presented better catalytic results as compared with FeP-LDH- $-\mathrm{NO}_{3}$ (runs 2 and 4, respectively) a probable consequence of the macroporous structure of the former support. In fact, the strategy employed during catalyst immobilization can tailor catalyst efficiency for different substrates. The morphology and textural properties of the support can direct the substrates to the catalytically active center in a different way. 18,36,50,76-78 $^{-10}$

Besides that, $\mathrm{FeP}$ immobilization protects the catalyst from the oxidative attack of another catalytically activated FeP, which avoids destruction of the catalytic species. In the

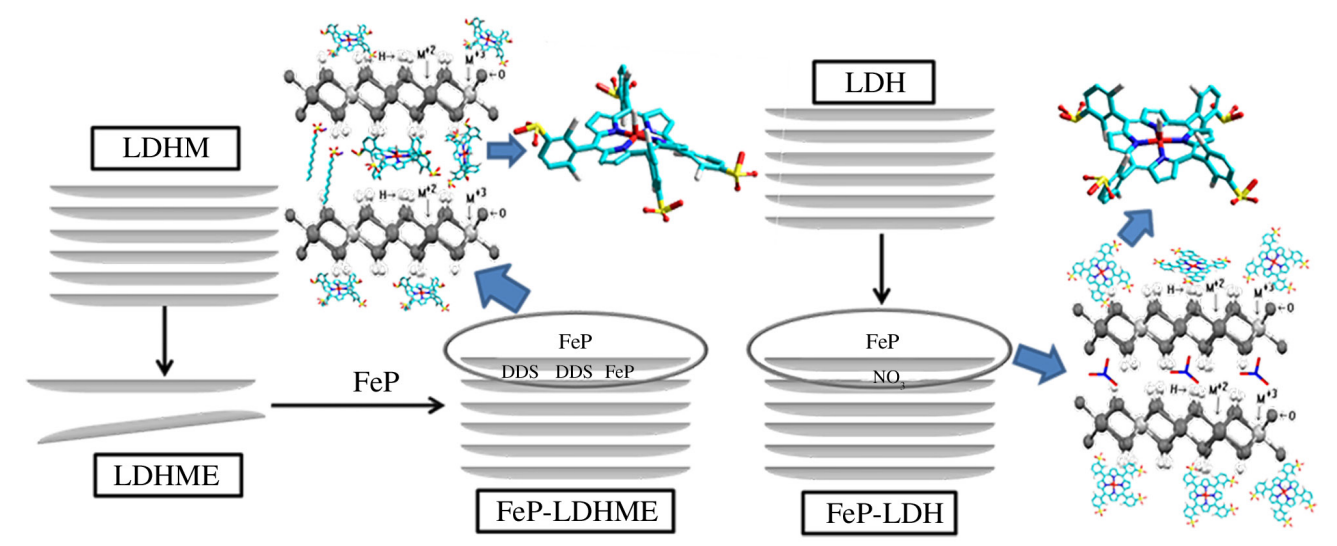

Figure 6. Schematic representation of the different modes of FeP immobilization in LDH. 
Table 1. (Z)-cyclooctene and cyclohexane oxidation by PhIO results catalyzed by FeP in homogeneous and heterogeneous media

\begin{tabular}{|c|c|c|c|c|}
\hline Reaction & Run & Epoxide / \% ${ }^{\mathrm{a}}$ & Alcohol / \% & Ketone $/ \%$ c \\
\hline [Fe(TDCSPP)Cl] + PhIO + substrate & 1 & $76 \pm 2.0$ & $13 \pm 1.0$ & trace \\
\hline FeP-LDHME + PhIO + substrate & 2 & $100 \pm 1.0$ & $35 \pm 4.7$ & 1.0 \\
\hline FeP-LDHME + PhIO + substrate first reuse & 3 & not performed & $30 \pm 5.0$ & trace \\
\hline FeP-LDH-NO ${ }_{3}+\mathrm{PhIO}+$ substrate & 4 & $77 \pm 1.1$ & $26 \pm 1.1$ & trace \\
\hline PhIO + substrate & 5 & $10 \pm 1.0$ & - & - \\
\hline $\mathrm{LDH}+\mathrm{PhIO}+$ substrate & 6 & $12 \pm 1.0$ & trace & trace \\
\hline $\mathrm{LDHM}+\mathrm{PhIO}+$ substrate & 7 & $16 \pm 2.3$ & trace & trace \\
\hline FeP-LDHM + PhIO + substrate ${ }^{\mathrm{d}}$ & 8 & 40 & 6 & trace \\
\hline
\end{tabular}

The reaction yield of ${ }^{a}$ cyclooctene/cyclooctene oxide; ${ }^{b}$ cyclohexane/cyclohexanol; and ${ }^{c}$ cyclohexane/cyclohexanone were calculated on the basis of the amount of PhIO used in each reaction. The results represent an average of at least triplicate reactions. Reaction conditions: $1 \mathrm{~h}$, room temperature, acetonitrile/dichloromethane $(1: 1 \mathrm{v} / \mathrm{v})$ as solvent, inert atmosphere, FeP/PhIO/substrate (cyclooctene or cyclohexane) molar ratio = 1:50:5000; ${ }^{\mathrm{d}}$ results from reference 41. Catalytic reaction performed with the same FeP immobilized in LHDM under reaction conditions similar to those adopt in this study, except for the $\mathrm{FeP} / \mathrm{PhIO} /$ substrate molar ratio $=1: 10: 1000$.

specific case of FeP-LDHME, the microporous structure of the support may have conferred better protection to the FeP, whereas the immobilized FeP remained on the surface of the layered crystals in FeP-LDH-NO 3 , as indicated by XRD analysis (Figure 2c).

Immobilized catalysts offer a number of advantages: control of the reaction medium, prevention of catalyst degradation, low cost (depending on the support), stability, and possibility of catalyst reuse and/or recycling.

Indeed, we have performed the catalysts reuse reactions that surprisingly afforded the best result in a new cyclohexane oxidation reaction (FeP-LDHME; run 3). Also, the obtained product yield was similar to that achieved with the freshly prepared solid catalyst (run 2). Therefore, this solid catalytic is potentially reusable in oxidation reactions, favoring heterogeneous catalysis over the homogeneous route.

The monitoring of the reaction solvent or the washing solutions resulting from the filtration of the catalyst FePLDHME was performed and no traces of porphyrin were detected by UV-Vis analysis. This fact allowed us to conclude that there was no leaching of the FeP after the first use or during the washing process and the reaction is truly performed in heterogeneous media.

In addition, FeP-LDH-NO $\mathrm{N}_{3}$ and FeP-LDHME (spectra FTIR) after catalysis reactions, the solids presented characteristic bands observed in the fresh catalysts, which seems to be a convincing evidence that the catalysts preserved its structure after the reaction, washing process and reuse. As the catalysts consist of very fine powder, after each reaction, around $10 \%$ of the solids is lost by manipulation, washing and drying.

Recently, we have verified that highly distorted immobilized MPs and MPs in solution afford better catalytic results. $^{22}$ This is because the presence of bulkier substituents in the porphyrin macrocycle can affect ring symmetry and distort the structure. ${ }^{22}$ This may influence the formation and stabilization of the active catalytic oxospecies in such a way that the more distorted porphyrin structure performs better than the less distorted one. ${ }^{22}$ In fact, distortions in the porphyrin skeleton can destabilize the macrocycle $\pi$ systems, thereby modulating their oxidation potentials. ${ }^{79-87}$ Hence, distinct structural configurations could also determine the catalytic outcome. ${ }^{78,79}$

The catalytic results achieved with the solid FeP-LDHME were also better than those reported by Halma et al. ${ }^{41}$ for FeP-LDHM (Table 1, run 8). ${ }^{41}$ In the former catalyst, the $\mathrm{FeP}$ acquired a more distorted arrangement due to exfoliation associated with the structure and macroporous morphology of LDHME, as evidenced by SEM.

\section{Conclusions}

This work described the preparation of two solid catalysts via immobilization of the anionic [Fe(TDCSPP)] in LDH supports, with the aim to compare the influence of supports with the same composition but different structures in the catalytic activity of the iron complex during the oxidation of two model substrates.

We selected a second generation ironporphyrin ${ }^{10}$ because the presence of electron-withdrawing groups on the phenyl substituents of the porphyrin ring made the catalyst more resistant to oxidative degradation as compared with simpler metalloporphyrins like the first-generation iron(III) tetraphenylporphyrin [Fe(TPP)] employed by Groves. ${ }^{11,14}$

We successfully immobilized the ironporphyrin on both LDHs (one LDH was obtained by co-precipitation; the other was prepared by using polystyrene beads as template). After calcinations to eliminate polystyrene, the latter solid presented a macroporous structure of oxides that regenerated the LDH structure after hydration. Additionally, this same FeP was also immobilized on $\mathrm{LDH}$ of $\mathrm{Mg} / \mathrm{Al}$ containing nitrate anions intercalated. Characterization of 
the solids obtained after immobilization/intercalation of the ironporphyrin by UV-Vis and FTIR spectroscopies and XRD analysis confirmed the presence of the iron complex in the LDH. The solids displayed good catalytic activity in heterogeneous catalysis; they furnished yields higher than those achieved in homogeneous medium.

\section{Supplementary Information}

Supplementary information (spectra FTIR of all the compounds prepared) is available free of charge at http:// jbcs.sbq.org.br.

\section{Acknowledgements}

The authors are grateful to Conselho Nacional de Desenvolvimento Científico e Tecnológico (CNPq), Coordenação de Aperfeiçoamento de Pessoal de Nível Superior (CAPES), Fundação Araucária, Fundação da Universidade Federal do Paraná (FUNPAR), Universidade Federal do Paraná (UFPR), and Université Blaise Pascal for financial support. The authors are also grateful to Centro de Microscopia Eletrônica from UFPR for the SEM analysis.

\section{References}

1. Montellano, P. R. O.; Cytochrome P450: Structure, Mechanism, and Biochemistry, $3^{\text {rd }}$ ed.; Kluwer Academic/Plenum Publishers: New York, USA, 2005.

2. Lohmann, W.; Anal. Bioanal. Chem. 2008, 391, 79.

3. Rittle, J.; Green, M. T.; Science 2010, 330, 933.

4. Guengerich, F. P.; Sohl, C. D.; Chowdhury, G.; Arch. Biochem. Biophys. 2011, 507, 126.

5. Rendic, S.; Guengerich, F. P.; Chem. Res. Toxicol. 2012, 25, 1316.

6. Mansuy, D.; C. R. Chimie 2007, 10, 392.

7. Ricoux, R.; Raffy, Q.; Mahy, J.-P.; C. R. Chimie 2007, 10, 684.

8. Nakagaki, S.; Castro, K. A. D. F.; Machado, G. S.; Halma, M.; Drechsel, S. M.; Wypych, F.; J. Braz. Chem. Soc. 2006, 17, 1672.

9. Kadish, K.; Smith, K.; Guillard, R.; The Porphyrins Handbook, Academic Press: New York, USA, 1999.

10. Dolphin, D.; Traylor, T. G.; Xie, L. Y.; Acc. Chem. Res. 1997, $30,251$.

11. Groves, J. T.; J. Inorg. Biochem. 2006, 100, 434.

12. Guo, C.; Liu, Q.; Liu, Y.; CN1405131-A 2003 and CN1191218-C 2005, available at http://worldwide.espacenet.com/ and http:// www.google.com/patents/CN1405131A?cl=en, accessed in October 2014.

13. Huang, G.; Luo, Z.-C.; Hu, Y.-D.; Guo, Y.-A.; Jiang, Y.-X.; Wei, S.-J.; Chem. Eng. J. 2012, 195-196, 165.

14. Groves, J. T.; Nemo, T. E.; Myers, R. S.; J. Am. Chem. Soc. 1979, 101, 1032.
15. Ucoski, G. M.; Castro, K. A. D. F.; Ciuffi, K. J.; Ricci, G. P.; Marques, J. A.; Nunes, F. S.; Nakagaki, S.; Appl. Catal., A 2011, 404, 120.

16. Doro, F. G.; Smith, J. R. L.; Ferreira, A. G.; Assis, M. D.; J. Mol. Catal. A: Chem. 2000, 164, 97.

17. Machado, G. S.; Castro, K. A. D. F.; de Lima, O. J.; Nassar, E. J.; Ciuffi, K. J.; Nakagaki, S.; Colloids Surf., A 2009, 349, 162.

18. Halma, M.; Castro, K. A. D. F.; Taviot-Gueho, C.; Prévot, V.; Forano, C.; Wypych, F.; Nakagaki, S.; J. Catal. 2008, 257, 233.

19. Moreira, M. S. M.; Martins, P. R.; Curi, R. B.; Nascimento, O. R.; Iamamoto, Y.; J. Mol. Catal. A: Chem. 2005, 233, 73.

20. Latifi, R.; Tahsini, L.; Karamzadeh, B.; Safari, N.; Nam, W.; de Visser, S. P.; Arch. Biochem. Biophys. 2011, 507, 4.

21. Santos, J. S. D.; Faria, A. L.; Amorin, P. M. D. S.; Luna, F. M. L.; Caiado, K. L.; Silva, D. O. C. E.; Sartoratto, P. P. C.; Assis, M. D.; J. Braz. Chem. Soc. 2012, 23, 1411.

22. Castro, K. A. D. F.; Simões, M. M. Q.; Neves, M. G. P. M. S.; Cavaleiro, J. A. S.; Wypych, F.; Nakagaki, S.; Catal. Sci. Technol. 2014, 4, 129.

23. Nakagaki, S.; Halma, M.; Bail, A.; Arízaga, G. G. C.; Wypych, F.; J. Colloid Interface Sci. 2005, 281, 417.

24. Nakagaki, S.; Wypych, F.; J. Colloid Interface Sci. 2007, 315, 142.

25. Nakagaki, S.; Ramos, A. R.; Benedito, F. L.; Peralta-Zamora, P. G.; Zarbin, A. J. G.; J. Mol. Catal. A: Chem. 2002, 185, 203.

26. Traylor, T. G.; Byun, Y. S.; Traylor, P. S.; Battioni, P.; Mansuy, D.; J. Am. Chem. Soc. 1991, 113, 7821.

27. Bedioui, F.; Coord. Chem. Rev. 1995, 144, 39.

28. Martinez-Lorente, M. A.; Battioni, P.; Kleemiss, W.; Bartoli, J. F.; Mansuy, D.; J. Mol. Catal. A: Chem. 1996, 113, 343.

29. Cady, S. S.; Pinnavaia, T. J.; Inorg. Chem. 1978, 17, 1501.

30. Benedito, F. L.; Nakagaki, S.; Saczk, A. A.; Peralta-Zamora, P. G.; Costa, C. M. M.; Appl. Catal., A 2003, 250, 1.

31. Ucoski, G. M.; Nunes, F. S.; Defreitas-Silva, G.; Idemori, Y. M.; Nakagaki, S.; Appl. Catal., A 2013, 459, 121.

32. Ferreira, G. K. B.; Castro, K. A. D. F.; Machado, G. S.; Ribeiro, R. R.; Ciuffi, K. J.; Ricci, G. P.; Marques, J. A.; Nakagaki, S.; J. Mol. Catal. A: Chem. 2013, 378, 263.

33. Silva, M.; Azenha, M. E.; Pereira, M. M.; Burrows, H. D.; Sarakha, M.; Forano, C.; Ribeiro, M. F.; Fernandes, A.; Appl. Catal., B 2010, 100, 1.

34. Machado, G. S.; Castro, K. A. D. F.; Wypych, F.; Nakagaki, S.; J. Mol. Catal. A: Chem. 2008, 283, 99.

35. Machado, G. S.; Groszewicz, P. B.; Castro, K. A. D. F.; Wypych, F.; Nakagaki, S.; J. Colloid Interface Sci. 2012, 374, 278.

36. Halma, M.; Bail, A.; Wypych, F.; Nakagaki, S.; J. Mol. Catal. A: Chem. 2006, 243, 44.

37. Moghadam, M.; Mirkhani, V.; Tangestaninejad, S.; Mohammdpoor-Baltork, I.; Kargar, H.; J. Mol. Catal. A: Chem. 2008, 288, 116. 
38. Huang, G.; Liu, S.-Y.; Guo, Y.-A.; Wang, A.-P.; Luo, J.; Cai, C.-C.; Appl. Catal., A 2009, 358, 173.

39. Nakagaki, S.; Benedito, F. L.; Wypych, F.; J. Mol. Catal. A: Chem. 2004, 217, 121.

40. Castro, K. A. D. F.; Bail, A.; Groszewicz, P. B.; Machado, G. S.; Schreiner, W. H.; Wypych, F.; Nakagaki, S.; Appl. Catal., A 2010, 386, 51.

41. Halma, M.; Castro, K. A. D. F.; Prévot, V.; Forano, C.; Wypych, F.; Nakagaki, S.; J. Mol. Catal. A: Chem. 2009, 310, 42.

42. Wypych, F.; Bubniak, G. A.; Halma, M.; Nakagaki, S.; J. Colloid Interface Sci. 2003, 264, 203.

43. Kovanda, F.; Jindová, E.; Lang, K.; Kubát, P.; Sedláková, Z.; Appl. Clay Sci. 2010, 48, 260.

44. Rives, V.; Angeles Ulibarri, M. A.; Coord. Chem. Rev. 1999, 181,61 .

45. Crepaldi, E. L.; Valim, J. B.; Quim. Nova 1998, 21, 300.

46. Inacio, J.; Taviot-Guého, C.; Forano, C.; Besse, J. P.; Appl. Clay Sci. 2001, 18, 255.

47. Li, F.; Zhang, L.; Evans, D. G.; Forano, C.; Duan, X.; Thermochim. Acta 2004, 424, 15.

48. Stanimirova, T.; Hibino, T.; Appl. Clay Sci. 2006, 31, 65.

49. Ishikawa, T.; Matsumoto, K.; Kandori, K.; Nakayama, T.; Colloids Surf., A 2007, 293, 135.

50. Machado, G. S.; Arízaga, G. G. C.; Wypych, F.; Nakagaki, S.; J. Catal. 2010, 274, 130.

51. Rafqah, S.; Chung, P. W.-W.; Forano, C.; Sarakha, M.; J. Photochem. Photobiol., A 2008, 199, 297.

52. Abello, S.; Medina, F.; Tichit, D.; Perez-Ramirez, J.; Cesteros, Y.; Salagre, P.; Sueiras, J. E.; Chem. Commun. 2005, 11, 1453.

53. Géraud, E.; Prévot, V.; Leroux, F.; J. Phys. Chem. Solids 2006, 67, 903.

54. Sharefkin, J. G.; Saltzmann, H.; Org. Synth. 1973, 5, 660.

55. Lindsey, J. S.; Schreiman, I. C.; Hsu, H. C.; Kearney, P. C.; Marguerettaz, A. M.; J. Org. Chem. 1987, 52, 827.

56. Turk, H.; Ford, W. T.; J. Org. Chem. 1991, 56, 1253.

57. Adler, A. D.; Longo, F. R.; Kampas, F.; Kim, J.; J. Inorg. Nucl. Chem. 1970, 32, 2443.

58. Kobayashi, H.; Higushi, T.; Kaizu, Y.; Osada, H.; Aoki, M.; Bull. Chem. Soc. Jpn. 1975, 48, 3137.

59. Hibino, T.; Kobayashi, M.; J. Mater. Chem. 2005, 15, 653.

60. Leroux, F.; Gachon, J.; Besse, J.-P.; J. Solid State Chem. 2004, 177, 245.

61. Frost, R. L.; Zhu, J.; He, H.; Yuan, P.; Tao, Q.; Shen, W.; Bostrom, T.; J. Colloid Interface Sci. 2008, 319, 498.

62. Halma, M.; Wypych, F.; Drechsel, S. M.; Nakagaki, S.; J. Porphyrins Phthalocyanines 2002, 6, 502.

63. Nakamoto, K.; Infrared and Raman Spectra of Inorganic and Coordination Compounds, $5^{\text {th }}$ ed.; John Wiley \& Sons, Inc.: Chicago, USA, 1997.

64. Whittaker, J. W.; Lipscomb, J. D.; Kent, T. A.; Munck, E.; J. Biol. Chem. 1984, 259, 4466.
65. Tsai, R.; Yu, C. A.; Gunsalus, I. C.; Peisach, J.; Blumberg, T. W.; Orme-Johnson, W. H.; Beinert, H.; Proc. Natl. Acad. Sci. U. S. A. 1970, 66, 1157.

66. Holman, T. R.; Juarez-Garcia, C.; Hendrich, M. P.; Que, L.; Munck, E.; J. Am. Chem. Soc. 1990, 112, 7611.

67. Krzystek, J.; Ozarowski, A.; Telser, J.; Coord.Chem. Rev. 2006, $250,2308$.

68. Castro, K. A. D. F.; Halma, M.; Machado, G. S.; Ricci, G. P.; Ucoski, G. M.; Ciuffi, K. J.; Nakagaki, S.; J. Braz. Chem. Soc. 2010, 21, 1329.

69. Guo, C.-C.; Huang, G.; Zhang, X.-B.; Guo, D.-C.; Appl. Catal., A 2003, 247, 261.

70. Nam, W.; Ryu, Y. O.; Song, W. J.; J. Biol. Inorg. Chem. 2004, 9, 654 .

71. Rebelo, S. L. H.; Gonçalves, A. R.; Pereira, M. M.; Simões, M. M. Q.; Neves, M. G. P. M. S.; Cavaleiro, J. A. S.; J. Mol. Catal. A: Chem., 2006, 256, 321.

72. Lane, B. S.; Burgess, K.; Chem. Rev. 2003, 103, 2457.

73. Lyons, J. E.; Ellis Jr, P. E.; Metalloporphyrins in Catalytic Oxidations; Sheldon, R. A., ed.; Marcel Dekker: New York, USA, 1994.

74. Appleton, A. J.; Evans, S.; Smith, J. R. L.; J. Chem. Soc., Perkin Trans. 2 1996, 2, 281.

75. Berkowitz, J.; Ellison, G. B.; Gutman, D.; J. Phys. Chem. 1994, 98, 2744.

76. Machado, G. S.; Wypych, F.; Nakagaki, S.; J. Colloid Interface Sci. 2012, 377, 379.

77. Thomas, J. M.; Raja, R.; Sankar, G.; Bell, R. G.; Acc. Chem. Res. 2001, 34, 191.

78. Nakagaki, S.; Xavier, C. R.; Wosniak, A. J.; Mangrich, A. S.; Wypych, F.; Cantão, M. P.; Denicoló, I.; Kubota, L. T.; Colloids Surf., A 2000, 168, 261.

79. Durval, H.; Bulach, V.; Fischer, J.; Renner, M. W.; Fajer, J.; Weiss, R.; J. Biol. Inorg. Chem. 1997, 2, 662.

80. Barkigia, K. M.; Chantranupong, L.; Smith, K. M.; Fajer, J.; J. Am. Chem. Soc. 1988, 110, 7566.

81. Barkigia, K. M.; Berber, M. D.; Fajer, J.; Medforth, C. J.; Renner, M. W.; Smith, K. M.; J. Am. Chem. Soc. 1990, 112, 8851.

82. Barkigia, K. M.; Renner, M. W.; Furenlid, L. R.; Medforth, C. J.; Smith, K. M.; Fajer, J.; J. Am. Chem. Soc. 1993, 115, 3627.

83. Renner, M. W.; Barkigia, K. M.; Zhang, Y.; Medforth, C. J.; Smith, K. M.; Fajer, J.; J. Am. Chem. Soc. 1994, 116, 8582.

84. Takeuchi, T.; Gray, H. B.; Goddard, W. A.; J. Am. Chem. Soc. 1994, 116, 9730.

85. Takeda, J.; Sato, M.; Chem. Lett. 1995, 24, 939.

86. Spiro, T.; J. Am. Chem. Soc. 1996, 118, 9452.

87. Tronrud, D. E.; Schmid, M. F.; Matthews, B. W.; J. Mol. Biol. 1986, $188,443$.

Submitted on: August 7, 2014 Published online: October 14, 2014 